\title{
Clinical outcomes of state-of-the-art percutaneous coronary revascularisation in patients with three-vessel disease: two- year follow-up of the SYNTAX II study
}

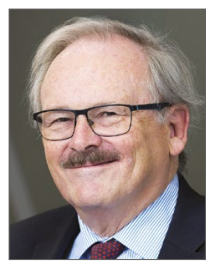

Patrick W. Serruys ${ }^{1,2 *}$, MD, PhD; Norihiro Kogame ${ }^{3}$, MD; Yuki Katagiri³, MD;

Rodrigo Modolo 3 , MD; Pawel E. Buszman ${ }^{4,5}, \mathrm{MD}, \mathrm{PhD}$; Andres Iniguez ${ }^{6}, \mathrm{MD}, \mathrm{PhD}$;

Javier Goicolea ${ }^{7}, \mathrm{MD}, \mathrm{PhD}$; David Hildick-Smith ${ }^{8}, \mathrm{MD}$; Andrzej Ochala ${ }^{5}, \mathrm{MD}, \mathrm{PhD}$;

Dariusz Dudek ${ }^{9}, \mathrm{MD}, \mathrm{PhD}$; Jan J. Piek ${ }^{3}, \mathrm{MD}$, PhD; Joanna J. Wykrzykowska ${ }^{3}, \mathrm{MD}, \mathrm{PhD}$;

Javier Escaned ${ }^{10}$, MD, PhD; Adrian P. Banning ${ }^{11}$, MBBS, MD; Vasim Farooq ${ }^{12}$, MBChB, PhD;

Yoshinobu Onuma², MD, PhD

1. Imperial College London, London, United Kingdom; 2. Thoraxcenter, Erasmus Medical Center, Rotterdam, the Netherlands;

3. Department of Cardiology, Amsterdam University Medical Center, Amsterdam, the Netherlands; 4. Center for Cardiovascular Research and Development, American Heart of Poland, Katowice, Poland; 5. Medical University of Silesia, Katowice, Poland; 6. Department of Cardiology, Hospital Meixoeiro, Pontevedra, Spain; 7. Department of Cardiology, Hospital Puerta de Hierro, Madrid, Spain; 8. Brighton \& Sussex University Hospitals NHS Trust, Brighton, United Kingdom; 9. Institute of Cardiology, Jagiellonian University, Krakow, Poland; 10. Hospital Clinico San Carlos IDISSC and Universidad Complutense de Madrid, Madrid, Spain; 11. Department of Cardiology, John Radcliffe Hospital, Oxford, United Kingdom, 12. The Newcastle upon Tyne Hospitals NHS Foundation Trust, Freeman Hospital, Newcastle upon Tyne, United Kingdom

P.W. Serruys and N. Kogame contributed equally to this work.

GUEST EDITOR: Alec Vahanian, MD, PhD; Department of Cardiology, Hôpital Bichat-Claude Bernard, and University Paris VII, Paris, France.

This paper also includes supplementary data published online at: https:/leurointervention.pcronline.com/doi/10.4244/EIJ-D-18-00980

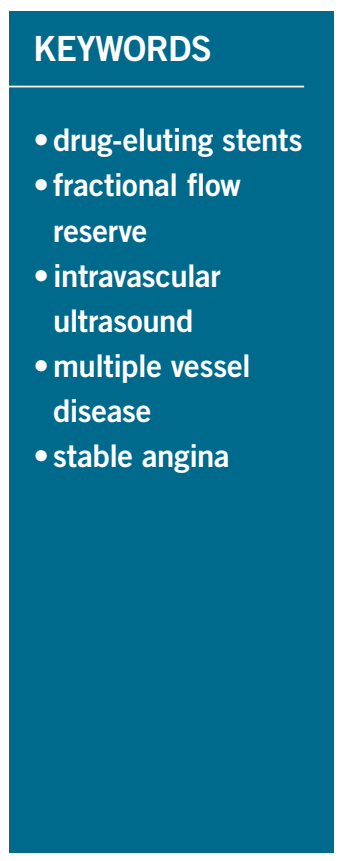

\begin{abstract}
Aims: The purpose of the study was to investigate whether the favourable outcomes of state-of-the-art PCI in the SYNTAX II trial, demonstrated at one year, were maintained at two-year follow-up.

Methods and results: The SYNTAX II study was a multicentre, single-arm study that investigated the impact of a contemporary PCI strategy on clinical outcomes in 454 patients with de novo three-vessel coronary artery disease, without left main disease. Clinical outcomes in SYNTAX II were compared to the predefined PCI (SYNTAX-I PCI) and coronary artery bypass graft (SYNTAX-I CABG) cohorts from the landmark SYNTAX trial (SYNTAX-I), selected on the basis of equipoise for long-term (four-year) mortality utilising the SYNTAX score II. At two years, major adverse cardiac and cerebrovascular events (MACCE: a composite of all-cause death, any stroke, myocardial infarction, or revascularisation) in SYNTAX II were significantly lower compared to SYNTAX-I PCI $(13.2 \%$ vs. $21.9 \%, \mathrm{p}=0.001)$. Furthermore, similar twoyear outcomes for MACCE were evident between SYNTAX II PCI and SYNTAX-I CABG $(13.2 \%$ vs. $15.1 \%, \mathrm{p}=0.42)$.
\end{abstract}

Conclusions: At two years, clinical outcomes with the SYNTAX II strategy remained superior to the predefined SYNTAX-I PCI cohort, and similar to the predefined SYNTAX-I CABG cohort.

\footnotetext{
*Corresponding author: Cardiovascular Science Division of the NHLI within Imperial College of Science, Technology and Medicine, South Kensington Campus, London, SW7 2AZ, United Kingdom. E-mail: patrick.w.j.c.serruys@gmail.com
} 


\section{Abbreviations}

$\begin{array}{ll}\text { ARC } & \text { Academic Research Consortium } \\ \text { CABG } & \text { coronary artery bypass grafting } \\ \text { DES } & \text { drug-eluting stent } \\ \text { FFR } & \text { fractional flow reserve } \\ \text { iFR } & \text { instantaneous wave-free ratio } \\ \text { MACCE } & \text { major adverse cardiac and cerebrovascular events } \\ \text { MI } & \text { myocardial infarction } \\ \text { Non-TVR } & \text { non-target vessel revascularisation } \\ \text { PCI } & \text { percutaneous coronary intervention } \\ \text { ST } & \text { stent thrombosis } \\ \text { 3VD } & \text { three-vessel disease }\end{array}$

\section{Introduction}

With the introduction of drug-eluting stents (DES), the efficacy of percutaneous coronary intervention (PCI) has improved compared to bare metal stents ${ }^{1}$. Despite this, five-year follow-up of the landmark SYNTAX-I (SYNergy between percutaneous coronary intervention with TAXus and cardiac surgery) trial demonstrated that PCI with first-generation DES was inferior to coronary artery bypass graft (CABG) surgery, being associated with a higher incidence of a composite of all-cause death, any stroke, or myocardial infarction (MI) (PCI 20.8\% vs. CABG 16.7\%, $\mathrm{p}=0.03)^{2}$.

In the de novo three-vessel disease (3VD) cohort of SYNTAX-I, patients with a low anatomical complexity (anatomic SYNTAX score $\leq 22$ ) were shown to have similar outcomes between CABG and PCI at five years. Conversely, in patients with more anatomically complex coronary artery disease (anatomic SYNTAX score $>22$ ), CABG was demonstrated to have superior clinical outcomes. As a reflection of these findings, 3VD with low anatomic SYNTAX score $(\leq 22)$ is now given a class Ia recommendation for PCI, with more complex coronary artery disease $(>22)$ given a class III recommendation for PCI, and patients recommended to undergo $\mathrm{CABG}^{3}$. Furthermore, due to the results of a recent patient-level meta-analysis ${ }^{3,4}$, guidelines downgrade patients with 3VD with a low SYNTAX score and diabetes mellitus to a class IIb recommendation for PCI, and class Ia for CABG.

Since the completion of the SYNTAX-I trial, major technical and procedural advances influencing PCI outcomes have taken place. The SYNTAX II trial investigated the impact of a contemporary PCI strategy (SYNTAX II strategy) on clinical outcomes in patients with de novo 3VD, compared to a pre-specified and matched population of the SYNTAX-I trial, utilising the SYNTAX score II to identify patients with equipoise for long-term mortality between CABG and PCI.

At one year, the SYNTAX II strategy was superior to predefined SYNTAX-I PCI with respect to major adverse cardiac and cerebrovascular events (MACCE: a composite of all-cause death, any stroke, MI, or revascularisation, $10.6 \%$ vs. $17.4 \%, \mathrm{p}=0.006$ ). Furthermore, the non-inferiority of the SYNTAX II strategy compared to SYNTAX-I CABG was demonstrated, with respect to oneyear MACCE $(10.6 \% \text { vs. } 11.2 \% \text {, p for non-inferiority }<0.001)^{5}$. In terms of a composite of all-cause death, any stroke, or MI, the SYNTAX II strategy was similar to predefined SYNTAX-I CABG
$(4.0 \%$ vs. $5.9 \%, \mathrm{p}=0.20)$. The long-term clinical outcomes of contemporary PCI remain to be proven.

The purpose of this paper was to investigate whether the favourable outcomes of state-of-the-art PCI in the SYNTAX II trial at one year were maintained at two-year follow-up.

Editorial, see page 219

\section{Methods \\ STUDY DESIGN}

The design for this trial has been described previously $y^{5,6}$. The clinical outcomes in SYNTAX II were compared with predefined PCI (SYNTAX-I PCI) and CABG (SYNTAX-I CABG) cohorts from SYNTAX-I. These patients were selected on the basis of equipoise for long-term four-year mortality between CABG and PCI utilising the SYNTAX score II.

Following the selection of patients utilising the SYNTAX score II, consensus of the Heart Team (cardiac surgeons and interventional cardiologists) - that equivalent anatomical revascularisation was achievable - was mandated. Only then was the patient eligible for recruitment in SYNTAX II. Coronary lesions agreed by the Heart Team as requiring revascularisation were identified as "target lesions". Coronary lesions agreed by the Heart Team as not requiring revascularisation were identified as "non-target lesions".

Target lesions for revascularisation in SYNTAX II were assessed with a hybrid instantaneous wave-free ratio (iFR)/fractional flow reserve (FFR) approach. Physiologically significant lesions were treated with the SYNERGYTM DES (Boston Scientific, Marlborough, MA, USA). Post-PCI intravascular ultrasound assessment was mandatory to optimise stent expansion and apposition, with a recommendation to use the modified MUSIC criteria $^{7}$. In addition, contemporary chronic total occlusion revascularisation techniques ${ }^{8}$ by dedicated operators, and guidelinedirected medical therapy, including antiplatelet therapy and high-intensity statin therapy ${ }^{3,9}$, were recommended. The patient's clinical status was assessed at discharge, and at one- and two-year follow-up. Extended yearly follow-up is planned up to five years.

The local ethics committee approved the study in all participating sites. All patients provided written informed consent before enrolment.

\section{ENDPOINTS}

MACCE was defined as a composite of all-cause death, any stroke, MI, or revascularisation.

The primary analysis was two-year MACCE in the SYNTAX II compared with the SYNTAX-I PCI cohort. Spontaneous MI was defined as new Q-waves or one plasma level of creatine kinase myocardial band (CK-MB) $5 \mathrm{x}$ ULN (or troponin $\geq 35$ ULN if CK-MB not available) ${ }^{10}$ in the context of clinical syndrome consistent with acute coronary syndrome ${ }^{11}$. Secondary endpoints included the individual components of MACCE and definite stent thrombosis (ST) according to Academic Research Consortium (ARC) definitions at two-year follow-up ${ }^{12}$. 
By the SYNTAX II trial design, non-target vessel revascularisation (non-TVR) at follow-up was classified as:

1. occurring in a non-target lesion, anatomically assessed by visual inspection at the time of screening by the Heart Team and agreed as not for revascularisation;

2. occurring in a deferred coronary lesion based on iFR/FFR at the index procedure.

As an additional exploratory analysis, two-year MACCE was compared with the predefined SYNTAX-I CABG cohort of the original SYNTAX-I trial. Adverse events were adjudicated by an independent clinical events committee.

\section{STATISTICAL ANALYSIS}

The statistical analysis for this trial has been described previously $^{5,6}$ and is summarised in Supplementary Appendix 1.

\section{Results}

\section{BASELINE AND PROCEDURAL CHARACTERISTICS}

Between February 2014 and November 2015, 454 patients out of 708 screened patients were enrolled in SYNTAX II ${ }^{13}$. In SYNTAX-I, 643 (58.8\%) patients with 3VD without left main disease had an equipoise recommendation for CABG or PCI based on the SYNTAX score II and were used as the comparator. Baseline and procedural characteristics and achievement of SYNTAX II strategy are shown in Supplementary Table 1-Supplementary
Table 3. In SYNTAX II, the distribution of the anatomic SYNTAX score was as follows: low $(\leq 22) 298$ patients $(65.6 \%)$; intermediate (23-32) 140 patients $(30.8 \%)$, high (>32) 16 patients $(3.5 \%)$.

In SYNTAX II, statins were used in $97.3 \%$ and $92.3 \%$ of patients at discharge and two-year follow-up, respectively. Dual antiplatelet therapy use involved $6.8 \%$ of patients at two-year follow-up.

\section{TWO-YEAR MACCE AND COMPONENTS}

At two years in SYNTAX II, five patients withdrew their consent and six patients were lost to follow-up, resulting in complete twoyear follow-up in $97.6 \%(\mathrm{n}=434)$. Comparatively, in SYNTAX-I PCI, six patients were lost to follow-up, resulting in complete two-year follow-up in $98.0 \%(n=309)$; in SYNTAX-I CABG, 25 patients were lost to follow-up, resulting in complete two-year follow-up in $92.5 \%(n=309)$.

Table 1 and Figure 1 show MACCE and its components at twoyear follow-up. The incidence of MACCE was significantly lower in SYNTAX II compared to SYNTAX-I PCI (13.2\% vs. 21.9\%; hazard ratio [HR] 0.57, 95\% confidence interval [CI]: 0.40-0.81], $\mathrm{p}=0.001$ ). This difference was driven by a reduction of $66 \%$ in any MI and $38 \%$ in any revascularisation. We found a trend towards lower incidences of all-cause death and stroke in SYNTAX II compared to SYNTAX-I PCI $(2.7 \%$ vs. $5.5 \%, \mathrm{p}=0.055,0.4 \%$ vs. $2.0 \%, \mathrm{p}=0.07$, respectively).

There was no difference in MACCE between SYNTAX II patients with low $(\leq 22)$ vs. intermediate or high $(>22)$ anatomical

Table 1. Two-year clinical outcomes between SYNTAX II and SYNTAX-I PCI.

\begin{tabular}{|c|c|c|c|c|}
\hline Outcome & $\begin{array}{l}\text { SYNTAX II } \\
(n=454)\end{array}$ & $\begin{array}{l}\text { SYNTAX-I PCI } \\
\quad(n=315)\end{array}$ & $\begin{array}{c}\text { Hazard ratio } \\
(95 \% \text { CI) }\end{array}$ & $p$-value \\
\hline MACCE* $\%$ (n) & $13.2 \%(59)$ & $21.9 \%(68)$ & $0.57(0.40-0.81)$ & 0.001 \\
\hline All-cause death, stroke and any MI, \% (n) & $4.7 \%(21)$ & $10.6 \%(33)$ & $0.43(0.25-0.74)$ & 0.002 \\
\hline All-cause death, $\%(n)$ & $2.7 \%(12)$ & $5.5 \%(17)$ & $0.48(0.23-1.02)$ & 0.055 \\
\hline Cardiac death, \% (n) & $1.4 \%(6)$ & $3.9 \%(12)$ & - & 0.025 \\
\hline Vascular death, \% (n) & $0.5 \%(2)$ & $0.3 \%(1)$ & - & 0.80 \\
\hline Non-cardiovascular death, \% (n) & $0.9 \%(4)$ & $1.3 \%(4)$ & - & 0.59 \\
\hline Stroke, \% (n) & $0.4 \%(2)$ & $2.0 \%(6)$ & $0.23(0.05-1.13)$ & 0.07 \\
\hline Ischaemic, \% (n) & $0.4 \%(2)$ & $1.4 \%(4)$ & - & 0.19 \\
\hline Haemorrhagic, \% (n) & $0.2 \%(1)$ & $0.7 \%(2)$ & - & 0.36 \\
\hline Any MI, \% (n) & $2.1 \%(9)^{\#}$ & $5.8 \%(18)$ & $0.34(0.15-0.76)$ & 0.008 \\
\hline Periprocedural MI, \% (n) & $0.2 \%(1)$ & $3.8 \%(12)$ & - & $<0.001$ \\
\hline Spontaneous MI, \% (n) & $1.6 \%(7)$ & $2.0 \%(6)$ & - & 0.66 \\
\hline Any revascularisation, \% (n) & $10.2 \%(45)$ & $15.7 \%(48)$ & $0.62(0.41-0.94)$ & 0.022 \\
\hline CABG, \% (n) & $1.1 \%(5)$ & $2.6 \%(8)$ & - & 0.12 \\
\hline $\mathrm{PCl}, \%(n)$ & $9.3 \%(41)$ & $14.1 \%(43)$ & - & 0.036 \\
\hline Definite stent thrombosis, \% (n) & $0.9 \%(4)$ & $2.9 \%(9)$ & 0.30 (0.09-0.99) & 0.048 \\
\hline Acute, \% (n) & $0.2 \%(1)$ & $0.0 \%(0)$ & - & 0.40 \\
\hline Subacute, \% (n) & $0.0 \%(0)$ & $1.6 \%(5)$ & - & 0.007 \\
\hline Late, \% (n) & $0.4 \%(2)$ & $1.0 \%(3)$ & - & 0.37 \\
\hline Very late, \% (n) & $0.2 \%(1)$ & $0.3 \%(1)$ & - & 0.78 \\
\hline Probable stent thrombosis, \% (n) & $0.2 \%(1)$ & NA & - & - \\
\hline
\end{tabular}

The event rates are based on Kaplan-Meier estimates. * MACCE was defined as all-cause death, any stroke, MI, or revascularisation. \# One MI occurred after enrolment before the index procedure. CABG: coronary artery bypass grafting; MACCE: major adverse cardiac and cerebrovascular events; $\mathrm{MI}$ : myocardial infarction; $\mathrm{PCl}$ : percutaneous coronary intervention 
A

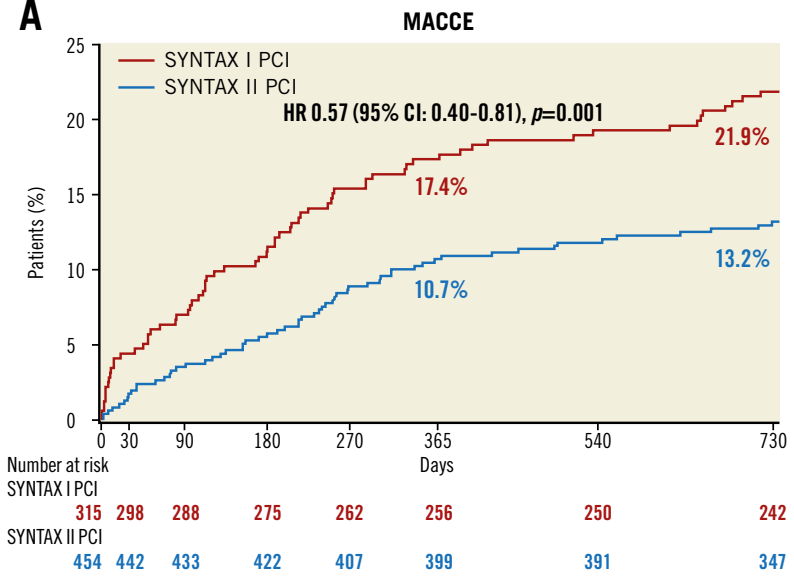

C

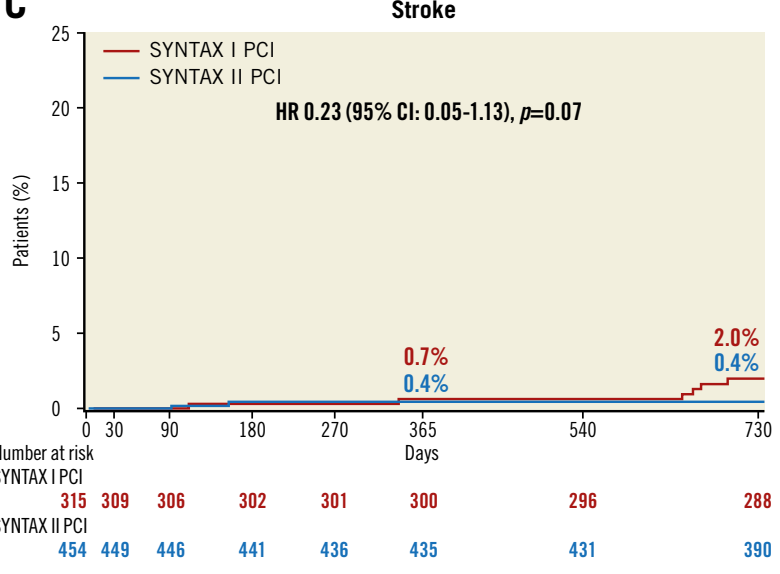

E

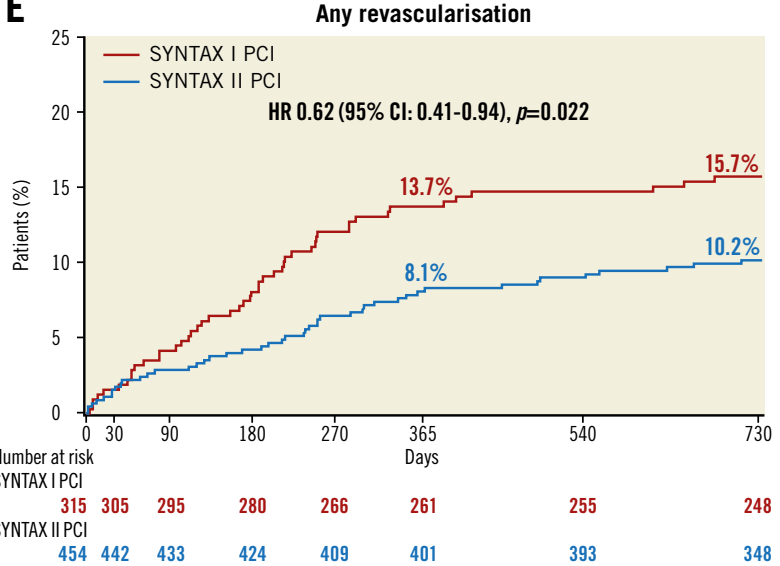

B

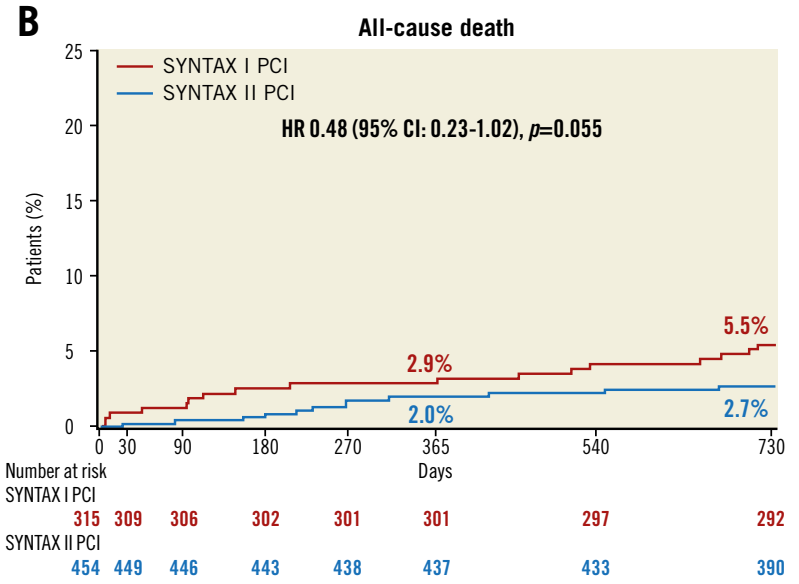

D

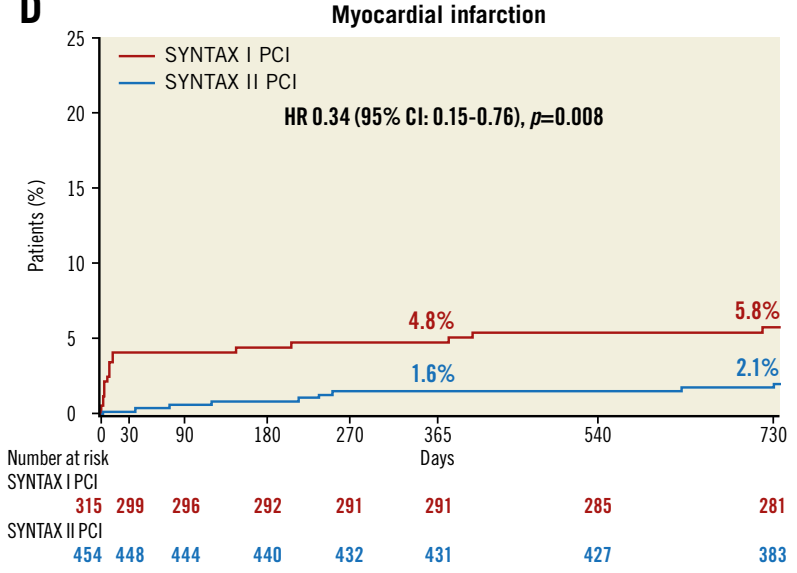

$\mathbf{F}$

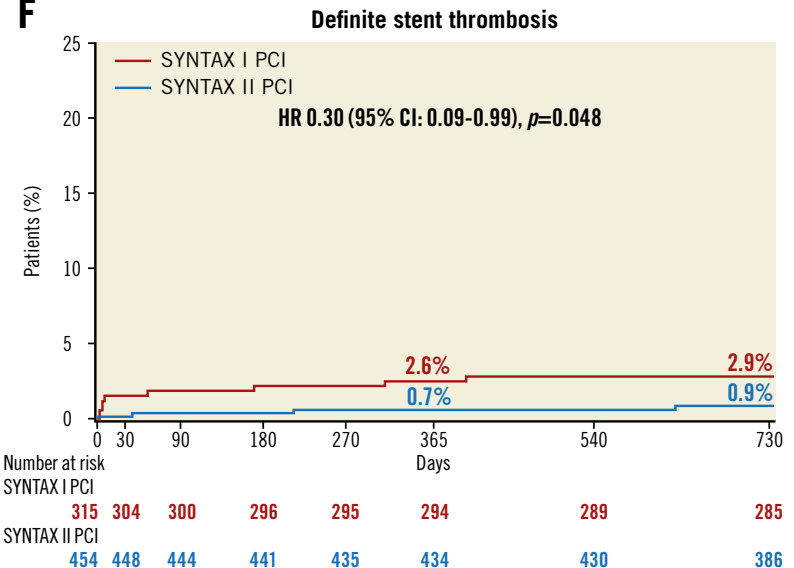

Figure 1. Two-year clinical outcomes among the study patients, compared with the SYNTAX-I PCI cohort. Kaplan-Meier curves are shown for SYNTAX II (blue) and SYNTAX-I PCI (red) for the composite endpoint of major adverse cardiac or cerebrovascular events (MACCE) (A), all-cause death (B), stroke (C), any myocardial infarction (D), any revascularisation (E), and definite stent thrombosis (F). MACCE was defined as all-cause death, any stroke, MI, or revascularisation.

SYNTAX score $(12.3 \%$ vs. $15.0 \%, \mathrm{p}=0.439)$ (Figure 2$)$, patients with vs. without any diabetes mellitus $(15.0 \%$ vs. $12.5 \%, \mathrm{p}=0.50)$, or patients with diabetes mellitus treated with insulin vs. without insulin $(18.4 \%$ vs. $13.4 \%, \mathrm{p}=0.46)$ (Supplementary Figure 1, Supplementary Figure 2).
In multivariate analysis, chronic obstructive pulmonary disease (HR 2.90, 95\% CI: 1.30-6.44), peripheral vascular disease (HR 3.38, 95\% CI: 1.32-8.62), and anatomical SYNTAX score per unit of score (HR 1.05, 95\% CI: 1.002-1.101) were significant (Supplementary Table 4). 


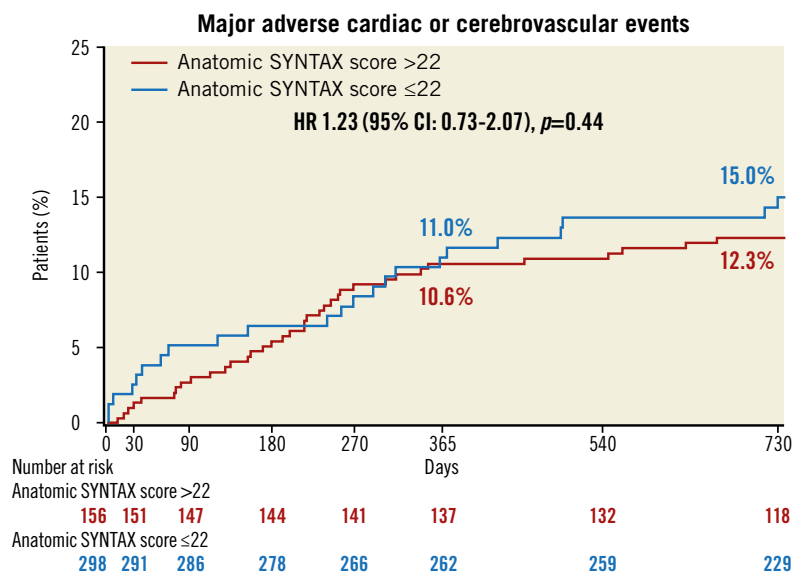

Figure 2. Kaplan-Meier cumulative incidence for major adverse cardiac or cerebrovascular events in SYNTAX II patients stratified by anatomic SYNTAX score $\leq 22$ (blue) and $>22$ (red).

\section{REPEAT REVASCULARISATION BETWEEN ONE-YEAR AND TWO-YEAR FOLLOW-UP}

The description of the revascularisation procedures in SYNTAX II is presented in Supplementary Table 5. Between one-year and two-year follow-up, 22 revascularisations occurred in 20 out of 1,559 lesions and two lesions were treated twice. Four lesions had already experienced a first event up to one year. The majority of revascularisations occurred in the initially stented lesions ( $77 \%, n=17$ events), whereas there were few events in the initially deferred lesions (14\%, $\mathrm{n}=3$ events) (Figure 3). No MI in the territory of the initially deferred lesions occurred.

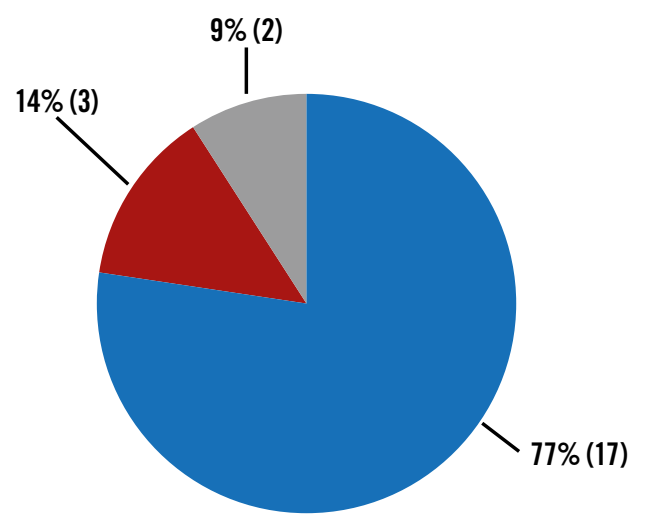

Deferred lesion

Others*

Stented lesion (In-stent restenosis)

Figure 3. Distribution of baseline lesion type that caused

revascularisation from one-year to two-year follow-up. In a total of 22 revascularisations, the majority of revascularisations occurred in the initially stented lesions $(77 \%, n=17$ events, blue), whereas there were few events in the initially deferred lesions $(14 \%, n=3$ events, red). *One revascularisation occurred in a distal lesion far from the initially stented lesion. In addition, one revascularisation of a CTO lesion was staged and not treated at the index procedure $(9 \%, n=2$ events, grey).

\section{STENT THROMBOSIS}

The incidence of definite ST in SYNTAX II was significantly lower compared to SYNTAX-I PCI $(0.9 \%$ vs. $2.9 \%$; HR 0.30 , 95\% CI: 0.09-0.99, $\mathrm{p}=0.048$ ] (Table 1, Figure 1). No difference was found in the incidence of late (between 30 days and one year) and very late ST (after one year) between groups. Between one- and two-year follow-up, only one ST occurred as MI in SYNTAX II.

\section{EXPLORATORY COMPARISON WITH SYNTAX-I CABG}

The exploratory comparison with the predefined SYNTAX-I CABG demonstrated a similar' incidence of MACCE at two years (SYNTAX II $13.2 \%$ vs. SYNTAX-I CABG 15.1\%; HR $0.85,95 \%$ CI: $0.58-1.25, p=0.42$ ) (Table 2, Figure 4). The incidence of stroke was significantly lower in SYNTAX II compared to SYNTAX-I CABG $(0.4 \%$ vs. $2.2 \%, \mathrm{p}=0.045)$. The incidence of all-cause revascularisation was similar $(10.2 \%$ vs. $8.4 \%, \mathrm{p}=0.41)$. We found a trend towards a higher incidence of non-TVR in SYNTAX II compared with SYNTAX-I CABG $(2.0 \%$ [9/454] vs. $0.6 \%[2 / 334], \mathrm{p}=0.12$ ).

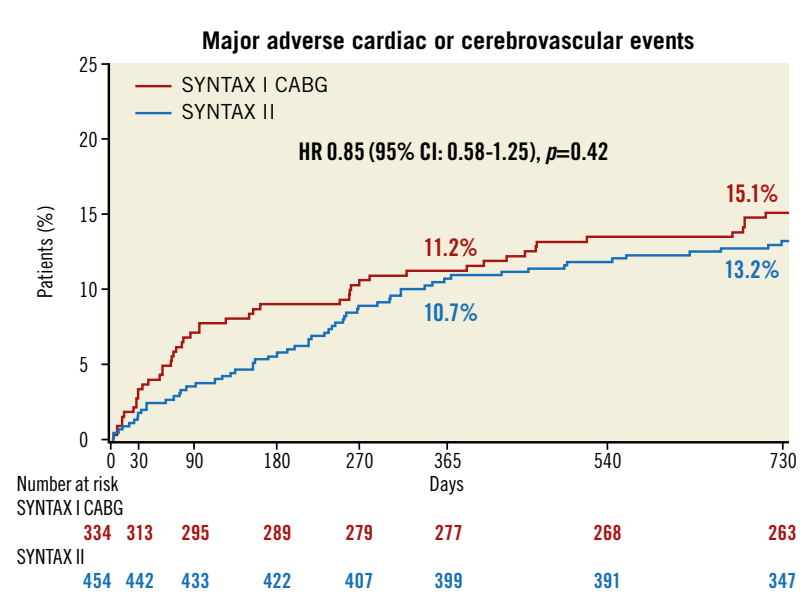

Figure 4. Two-year major adverse cardiac or cerebrovascular events among the study patients, compared with the SYNTAX-I CABG cohort. Kaplan-Meier curves are shown for SYNTAXII (blue) and SYNTAX-I CABG (red) for the exploratory composite endpoint of major adverse cardiac or cerebrovascular events (MACCE). MACCE was defined as all-cause death, any stroke, MI, or revascularisation.

Looking at the details of nine non-TVR in SYNTAX II, seven non-TVR occurred in initially deferred lesions based on iFR/FFR at the index procedure. One non-TVR occurred in an anatomically non-target lesion at the index procedure. The second patient developed unstable angina before a planned staged procedure at day 2 .

At the time of revascularisation (day 544 and day 303, respectively), one lesion was justified with FFR of 0.76 , and one lesion had become a total occlusion. 
Table 2. Two-year clinical outcomes between SYNTAX II and SYNTAX-I CABG.

\begin{tabular}{|c|c|c|c|c|}
\hline Outcome & $\begin{array}{l}\text { SYNTAX II } \\
(n=454)\end{array}$ & $\begin{array}{c}\text { SYNTAX-I CABG } \\
(n=334)\end{array}$ & $\begin{array}{c}\text { Hazard ratio } \\
(95 \% \mathrm{CI})\end{array}$ & $p$-value \\
\hline MACCE* $\%(n)$ & $13.2 \%(59)$ & $15.1 \%(48)$ & $0.85(0.58-1.25)$ & 0.42 \\
\hline All-cause death, stroke and any MI, \% (n) & $4.7 \%(21)$ & $8.2 \%(26)$ & - & 0.045 \\
\hline All-cause death, $\%(n)$ & $2.7 \%(12)$ & $5.1 \%(16)$ & $0.52(0.25-1.11)$ & 0.09 \\
\hline Cardiac death, \% (n) & $1.4 \%(6)$ & $2.8 \%(9)$ & - & 0.14 \\
\hline Vascular death, \% (n) & $0.5 \%(2)$ & $0.7 \%(2)$ & - & 0.71 \\
\hline Non-cardiovascular death, \% (n) & $0.9 \%(4)$ & $1.7 \%(5)$ & - & 0.37 \\
\hline Stroke, \% (n) & $0.4 \%(2)$ & $2.2 \%(7)$ & $0.20(0.04-0.96)$ & 0.045 \\
\hline Ischaemic, \% (n) & $0.4 \%(2)$ & $1.9 \%(6)$ & - & 0.052 \\
\hline Haemorrhagic, \% (n) & $0.2 \%(1)$ & $0.3 \%(1)$ & - & 0.79 \\
\hline Any MI, \% (n) & $2.1 \%(9)$ & $2.2 \%(7)$ & $0.91(0.34-2.44)$ & 0.85 \\
\hline Periprocedural MI, \% (n) & $0.2 \%(1)$ & $1.5 \%(5)$ & - & 0.04 \\
\hline Spontaneous MI, \% (n) & $1.6 \%(7)$ & $0.7 \%(2)$ & - & 0.25 \\
\hline Any revascularisation, \% (n) & $10.2 \%(45)$ & $8.4 \%(26)$ & $1.23(0.76-1.99)$ & 0.41 \\
\hline CABG, \% (n) & $1.1 \%(5)$ & $1.0 \%(3)$ & - & 0.83 \\
\hline $\mathrm{PCl}, \%(n)$ & $9.3 \%(41)$ & $7.8 \%(24)$ & - & 0.46 \\
\hline
\end{tabular}

\section{Discussion}

The main findings of the study are the following: 1) PCI undertaken with the SYNTAX II strategy was associated with superior outcomes compared with the predefined SYNTAX-I PCI cohort, with a lower incidence of MACCE predominantly driven by a reduction in MI, all-cause revascularisation, and definite ST at two-year follow-up; 2) the two-year outcomes of patients with intermediate or high anatomical SYNTAX score $(>22)$, treated with PCI using the SYNTAX score II risk stratification algorithm, were similar to those observed in patients with the low anatomical SYNTAX score $(\leq 22) ; 3)$ the two-year outcome of deferred lesions on the basis of a hybrid iFR/FFR approach was benign; 4) in an exploratory analysis at two years, PCI with the SYNTAX II strategy was similar to the predefined SYNTAX-I CABG cohort, with respect to the incidence of MACCE.

Even if some of the elements of the SYNTAX II strategy were not fully applied (Supplementary Table 3), it is important for clinicians to realise that these results were not just the outcomes of contemporary PCI, but instead were only obtained by "best of PCI practice", which includes adoption of the SYNTAX II strategy in a high proportion if not all $3 \mathrm{VD}$ cases.

As shown in the FAME trial, physiology-guided revascularisation in patients with multivessel disease resulted in a significant reduction of a composite of death or MI at two-year follow-up after the index procedure compared with angiography-guided revascularisation ${ }^{14}$. In the present study, the proportion of the initially deferred lesions revascularised between one-year and twoyear follow-up was quite low (14\%, 3/22 lesions). Notably, no MI in the territory of the initially deferred lesions occurred. While recent trial data have revealed excellent outcomes of revascularisation deferral based on either iFR or FFR in low- and intermediate-risk populations ${ }^{15}$, the findings in the SYNTAX II trial demonstrate that safe decision making can also be performed in the high-risk 3VD patients who have been selected on the basis of equipoise for long-term mortality between CABG and PCI utilising the SYNTAX score II. Furthermore, as the decision to perform or defer revascularisation was based on iFR in more than $75 \%$ of interrogated stenoses, the SYNTAX II study provides indirect support to the safety of resting pressure-derived indices to decide revascularisation in this complex patient subset.

In the exploratory comparison with the predefined SYNTAX-I CABG cohort, no significant differences were shown in the incidence of MACCE between groups. The similar outcomes were maintained from one-year to two-year follow-up. Comparatively, the BEST trial, in which second-generation everolimus-eluting stents were used to treat multivessel disease, demonstrated that CABG was associated with a lower incidence of MACCE at five years, driven by a reduction in the incidence of MI and repeat revascularisation ${ }^{16}$. In the present study, the incidence of MI and repeat revascularisation in the SYNTAX II group remained similar to the SYNTAX-I CABG cohort at two years.

In addition, the incidence of definite ST at two years in SYNTAX II $(0.9 \%)$ was comparable with current all-comers trials with newer-generation DES (BIOSCIENCE: 0.8 to $1.1 \%$, BIORESORT: 0.6 to $1.0 \%$, DESSOLVE III: 0.6 to $1.0 \%)^{17-19}$, and was lower than in the ARTS II trial $(2.0 \%)^{20}$.

The favourable outcomes of the SYNTAX II strategy are exemplified by the absence of convergence and crossing over of endpoints at two years (Figure 4) which was evident in ARTS I and II. The incidence of non-TVR in SYNTAX II was numerically higher compared to SYNTAX-I CABG $(2.0 \%$ [9/454] vs. 0.6\% [2/334], $\mathrm{p}=0.12$ ). In SYNTAX II, the majority of non-TVR occurred in initially deferred lesions at the index procedure with negative iFR/ FFR values $(7 / 9,77.8 \%)$. In addition, two patients $(2 / 9,22.2 \%)$ at follow-up were justified by either anatomical character (total occlusion) or reduced FFR. 


\section{Study limitations}

Firstly, this is a single-arm study comparing a contemporary PCI strategy with an historical control group (SYNTAX-I). Secondly, because of the observed advantage of CABG in females and young patients in the landmark SYNTAX trial, the SYNTAX score II resulted in a low proportion of these subgroups of patients in the present study. Thirdly, there is a nine-year lapse of time between the enrolment periods of SYNTAX I and II; with recent improvements in surgical techniques and concomitant medication, it is possible that the clinical results of a randomised trial could be at variance with the results of this present observational study ${ }^{21,22}$. Fourthly, although the use of coronary physiology was mandatory in lesions intended to be treated, mild stenoses not included in the anatomic SYNTAX score (i.e., $<50 \%$ ) may potentially be associated with physiological significance and were not systematically assessed by iFR/FFR. Finally, these data cannot be extrapolated to patients with left main disease and to 3VD patients without SYNTAX score II equipoise.

\section{Conclusions}

At two years, the SYNTAX II strategy was associated with improved clinical outcomes compared with the PCI performed in patients with 3VD without left main disease matched by the SYNTAX score II from the original SYNTAX-I trial. At two years, clinical outcomes of the SYNTAX II strategy compared favourably with the SYNTAX-I CABG cohort. Later follow-up is warranted, in addition to a randomised trial (with five to 10 years of follow-up) which will be mandatory to shed light on the respective values of contemporary and future surgical or percutaneous revascularisation treatments.

\section{Impact on daily practice}

This study offers an attractive option of a revascularisation strategy in predefined patients with de novo 3VD (SYNTAX score II inclusion) even if the patients have moderate to severe anatomical complexity (anatomic SYNTAX score $>22$ ).

\section{Guest Editor}

This paper was guest edited by Alec Vahanian, MD, PhD; Department of Cardiology, Hôpital Bichat-Claude Bernard, and University Paris VII, Paris, France.

\section{Funding}

The SYNTAX II trial was an investigator-initiated study, sponsored by the European Cardiovascular Research Institute (ECRI, Rotterdam, the Netherlands) with unrestricted research grants from Volcano and Boston Scientific. The grant givers were not involved in the study design, data collection, data interpretation or writing of the manuscript.

\section{Conflict of interest statement}

P.W. Serruys reports being a consultant for Volcano and a member of the advisory board of Abbott Vascular. J. Piek reports being a consultant for Philips/Volcano and being a member of the advisory board of Abbott Vascular. J. Escaned reports being a consultant for Abbott, Philips/Volcano, and Boston Scientific. A. Banning reports receiving lecture fees from Abbott Vascular, Medtronic, and Boston Scientific, and grant support from Boston Scientific. Y. Onuma reports being a member of the advisory board of Abbott Vascular. The other authors have no conflicts of interest to declare. The Guest Editor is a consultant for Edwards Lifesciences.

\section{References}

1. Morice MC, Serruys PW, Sousa JE, Fajadet J, Ban Hayashi E, Perin M, Colombo A, Schuler G, Barragan P, Guagliumi G, Molnar F, Falotico R; RAVEL Study Group. Randomized Study with the Sirolimus-Coated Bx Velocity Balloon-Expandable Stent in the Treatment of Patients with de Novo Native Coronary Artery Lesions. A randomized comparison of a sirolimus-eluting stent with a standard stent for coronary revascularization. $N$ Engl J Med. 2002;346:1773-80.

2. Mohr FW, Morice MC, Kappetein AP, Feldman TE, Stahle E, Colombo A, Mack MJ, Holmes DR Jr, Morel MA, Van Dyck N, Houle VM, Dawkins KD, Serruys PW. Coronary artery bypass graft surgery versus percutaneous coronary intervention in patients with three-vessel disease and left main coronary disease: 5-year follow-up of the randomised, clinical SYNTAX trial. Lancet. 2013;381:629-38.

3. Neumann FJ, Sousa-Uva M, Ahlsson A, Alfonso F, Banning AP, Benedetto U, Byrne RA, Collet JP, Falk V, Head SJ, Jüni P, Kastrati A, Koller A, Kristensen SD, Niebauer J, Richter DJ, Seferovic PM, Sibbing D, Stefanini GG, Windecker S, Yadav R, Zembala MO; ESC Scientific Document Group. 2018 ESC/EACTS Guidelines on myocardial revascularization. Eur Heart J. 2018;40:87-165.

4. Head SJ, Milojevic M, Daemen J, Ahn JM, Boersma E, Christiansen EH, Domanski MJ, Farkouh ME, Flather M, Fuster V, Hlatky MA, Holm NR, Hueb WA, Kamalesh M, Kim YH, Makikallio T, Mohr FW, Papageorgiou G, Park SJ, Rodriguez AE, Sabik JF 3rd, Stables RH, Stone GW, Serruys PW, Kappetein AP. Mortality after coronary artery bypass grafting versus percutaneous coronary intervention with stenting for coronary artery disease: a pooled analysis of individual patient data. Lancet. 2018;391: 939-48.

5. Escaned J, Collet C, Ryan N, De Maria GL, Walsh S, Sabate M, Davies J, Lesiak M, Moreno R, Cruz-Gonzalez I, Hoole SP, Ej West N, Piek JJ, Zaman A, Fath-Ordoubadi F, Stables RH, Appleby C, van Mieghem N, van Geuns RJ, Uren N, Zueco J, Buszman P, Iniguez $\mathrm{A}$, Goicolea $\mathrm{J}$, Hildick-Smith $\mathrm{D}$, Ochala $\mathrm{A}$, Dudek $\mathrm{D}$, Hanratty C, Cavalcante R, Kappetein AP, Taggart DP, van Es GA, Morel MA, de Vries T, Onuma Y, Farooq V, Serruys PW, Banning AP. Clinical outcomes of state-of-the-art percutaneous coronary revascularization in patients with de novo three vessel disease: 1-year results of the SYNTAX II study. Eur Heart J. 2017;38:3124-34.

6. Escaned J, Banning A, Farooq V, Echavarria-Pinto M, Onuma Y, Ryan N, Cavalcante R, Campos CM, Stanetic BM, Ishibashi Y, Suwannasom P, Kappetein AP, Taggart D, Morel MA, 
van Es GA, Serruys PW. Rationale and design of the SYNTAX II trial evaluating the short to long-term outcomes of state-of-the-art percutaneous coronary revascularisation in patients with de novo three-vessel disease. EuroIntervention. 2016;12:e224-34.

7. de Jaegere P, Mudra H, Figulla H, Almagor Y, Doucet S, Penn I, Colombo A, Hamm C, Bartorelli A, Rothman M, Nobuyoshi M, Yamaguchi T, Voudris V, DiMario C, Makovski S, Hausmann D, Rowe S, Rabinovich S, Sunamura M, van Es GA. Intravascular ultrasound-guided optimized stent deployment. Immediate and 6 months clinical and angiographic results from the Multicenter Ultrasound Stenting in Coronaries Study (MUSIC Study). Eur Heart J. 1998;19:1214-23.

8. Sianos G, Werner GS, Galassi AR, Papafaklis MI, Escaned J, Hildick-Smith D, Christiansen EH, Gershlick A, Carlino M, Karlas A, Konstantinidis NV, Tomasello SD, Di Mario C, Reifart N; EuroCTO Club. Recanalisation of chronic total coronary occlusions: 2012 consensus document from the EuroCTO club. EuroIntervention. 2012;8:139-45.

9. Iqbal J, Zhang YJ, Holmes DR, Morice MC, Mack MJ, Kappetein AP, Feldman T, Stahle E, Escaned J, Banning AP, Gunn JP, Colombo A, Steyerberg EW, Mohr FW, Serruys PW. Optimal medical therapy improves clinical outcomes in patients undergoing revascularization with percutaneous coronary intervention or coronary artery bypass grafting: insights from the Synergy Between Percutaneous Coronary Intervention with TAXUS and Cardiac Surgery (SYNTAX) trial at the 5-year follow-up. Circulation. 2015;131:1269-77.

10. Moussa ID, Klein LW, Shah B, Mehran R, Mack MJ, Brilakis ES, Reilly JP, Zoghbi G, Holper E, Stone GW; Society for Cardiovascular Angiography and Interventions. Consideration of a new definition of clinically relevant myocardial infarction after coronary revascularization: an expert consensus document from the Society for Cardiovascular Angiography and Interventions (SCAI). Catheter Cardiovasc Interv. 2014;83:27-36.

11. Serruys PW, Morice MC, Kappetein AP, Colombo A, Holmes DR, Mack MJ, Ståhle E, Feldman TE, van den Brand M, Bass EJ, Van Dyck N, Leadley K, Dawkins KD, Mohr FW; SYNTAX Investigators. Percutaneous coronary intervention versus coronary-artery bypass grafting for severe coronary artery disease. N Engl J Med. 2009;360:961-72..

12. Cutlip DE, Windecker S, Mehran R, Boam A, Cohen DJ, van Es GA, Steg PG, Morel MA, Mauri L, Vranckx P, McFadden E, Lansky A, Hamon M, Krucoff MW, Serruys PW; Academic Research Consortium. Clinical end points in coronary stent trials: a case for standardized definitions. Circulation. 2007;115:2344-51.

13. Campos CM, Stanetic BM, Farooq V, Walsh S, Ishibashi Y, Onuma Y, Garcia-Garcia HM, Escaned J, Banning A, Serruys PW; SYNTAX II Study Group. Risk stratification in 3-vessel coronary artery disease: Applying the SYNTAX Score II in the Heart Team Discussion of the SYNTAX II trial. Catheter Cardiovasc Interv. 2015;86:E229-38

14. Pijls NH, Fearon WF, Tonino PA, Siebert U, Ikeno F, Bornschein B, van't Veer M, Klauss V, Manoharan G, Engstrom T,
Oldroyd KG, Ver Lee PN, MacCarthy PA, De Bruyne B; FAME Study Investigators. Fractional flow reserve versus angiography for guiding percutaneous coronary intervention in patients with multivessel coronary artery disease: 2-year follow-up of the FAME (Fractional Flow Reserve Versus Angiography for Multivessel Evaluation) study. J Am Coll Cardiol. 2010;56:177-84.

15. Escaned J, Ryan N, Mejia-Renteria H, Cook CM, Dehbi HM, Alegria-Barrero E, Alghamdi A, Al-Lamee R, Altman J, Ambrosia A, Baptista SB, Bertilsson M, Bhindi R, Birgander M, Bojara W, Brugaletta S, Buller C, Calais F, Silva PC, Carlsson J, Christiansen EH, Danielewicz M, Di Mario C, Doh JH, Erglis A, Erlinge D, Gerber RT, Going O, Gudmundsdottir I, Harle T, Hauer D, Hellig F, Indolfi C, Jakobsen L, Janssens L, Jensen J, Jeremias A, Kåregren A, Karlsson AC, Kharbanda RK, Khashaba A, Kikuta Y, Krackhardt F, Koo BK, Koul S, Laine M, Lehman SJ, Lindroos P, Malik IS, Maeng M, Matsuo H, Meuwissen M, Nam CW, Niccoli G, Nijjer SS, Olsson H, Olsson SE, Omerovic E, Panayi G, Petraco R, Piek JJ, Ribichini F, Samady H, Samuels B, Sandhall L, Sapontis J, Sen S, Seto AH, Sezer M, Sharp ASP, Shin ES, Singh J, Takashima H, Talwar S, Tanaka N, Tang K, Van Belle E, van Royen N, Varenhorst C, Vinhas H, Vrints CJ, Walters D, Yokoi H, Fröbert O, Patel MR, Serruys P, Davies JE, Götberg M. Safety of the Deferral of Coronary Revascularization on the Basis of Instantaneous Wave-Free Ratio and Fractional Flow Reserve Measurements in Stable Coronary Artery Disease and Acute Coronary Syndromes. JACC Cardiovasc Interv. 2018; 11:1437-49.

16. Park SJ, Ahn JM, Kim YH, Park DW, Yun SC, Lee JY, Kang SJ, Lee SW, Lee CW, Park SW, Choo SJ, Chung CH, Lee JW, Cohen DJ, Yeung AC, Hur SH, Seung KB, Ahn TH, Kwon HM, Lim DS, Rha SW, Jeong MH, Lee BK, Tresukosol D, Fu GS, Ong TK; BEST Trial Investigators. Trial of everolimus-eluting stents or bypass surgery for coronary disease. $N$ Engl J Med. 2015;372:1204-12.

17. Zbinden R, Piccolo R, Heg D, Roffi M, Kurz DJ, Muller O, Vuilliomenet A, Cook S, Weilenmann D, Kaiser C, Jamshidi P, Franzone A, Eberli F, Juni P, Windecker S, Pilgrim T. Ultrathin Strut Biodegradable Polymer Sirolimus-Eluting Stent Versus Durable-Polymer Everolimus-Eluting Stent for Percutaneous Coronary Revascularization: 2-Year Results of the BIOSCIENCE Trial. J Am Heart Assoc. 2016;5:e03255.

18. Kok MM, Zocca P, Buiten RA, Danse PW, Schotborgh CE, Scholte M, Hartmann M, Stoel MG, van Houwelingen G, Linssen GCM, Doggen CJM, von Birgelen C. Two-year clinical outcome of all-comers treated with three highly dissimilar contemporary coronary drug-eluting stents in the randomised BIORESORT trial. EuroIntervention. 2018;14:915-23.

19. Katagiri Y, Onuma Y, Lurz P, Buszman P, Piek JJ, Wykrzykowska JJ, Asano T, Kogame N, Takahashi K, Chang CC, de Winter RJ, Serruys PW, Wijns W; Collaborators. Two-year follow-up of the DESSOLVE III trial: bioabsorbable polymer sirolimus-eluting stent vs. durable polymer everolimus-eluting stent. EuroIntervention. 2019 Feb 5. [Epub ahead of print]. 
20. Serruys PW, Onuma Y, Garg S, Vranckx P, De Bruyne B, Morice MC, Colombo A, Macaya C, Richardt G, Fajadet J, Hamm C, Schuijer M, Rademaker T, Wittebols K, Stoll HP; ARTS II Investigators. 5-year clinical outcomes of the ARTS II (Arterial Revascularization Therapies Study II) of the sirolimus-eluting stent in the treatment of patients with multivessel de novo coronary artery lesions. J Am Coll Cardiol. 2010;55:1093-101.

21. Gaudino M, Taggart DP. What is new in the armamentarium of coronary surgeons to compete with PCI? EuroIntervention. 2018;14:e387-9.

22. Banning AP, Serruys PW. The ball is now in our court. EuroIntervention. 2018;14:739-41.

\section{Supplementary data}

Supplementary Appendix 1. Statistical analysis.

Supplementary Table 1. Baseline clinical characteristics.

Supplementary Table 2. Lesion and procedural characteristics and medication.
Supplementary Table 3. Achievement of SYNTAX II strategy.

Supplementary Table 4. Univariate and multivariate independent predictors of two-year MACCE in SYNTAX II.

Supplementary Table 5. Revascularisation at two years in the SYNTAX II study.

Supplementary Figure 1. Kaplan-Meier cumulative incidence for major adverse cardiac or cerebrovascular events in SYNTAX II patients stratified by diabetes mellitus and nondiabetes mellitus.

Supplementary Figure 2. Kaplan-Meier cumulative incidence for major adverse cardiac or cerebrovascular events in SYNTAX II patients with diabetes mellitus stratified by insulin treated and non-insulin treated.

The supplementary data are published online at:

https://eurointervention.pcronline.com/

doi/10.4244/EIJ-D-18-00980 


\section{Supplementary data}

\section{Supplementary Appendix 1. Statistical analysis}

Continuous variables are presented as mean \pm standard deviation or median (interquartile range $[\mathrm{IQR}]$ ) and compared with the Student's t-test or Mann-Whitney test as appropriate. Categorical variables are presented as counts and percentages and compared with the chisquared test.

The outcome analyses were performed according to the intention-to-treat principle and are presented as Kaplan-Meier estimates and compared with Cox proportional hazards models. A separate multivariate analysis was performed to determine independent predictors of MACCE within the SYNTAX II population only. The following variables were tested on a per-patient univariate analysis to determine suitability for inclusion in the multivariate model: age, sex, diabetes mellitus, current smoking, previous MI, hypertension, hyperlipidaemia, creatinine clearance, ejection fraction, peripheral vascular disease, chronic obstructive pulmonary disease (COPD) and anatomic SYNTAX score. Finally, a multivariate Cox proportional hazards model was built using the univariate predictors with $\mathrm{p}$-value $<0.25$. A pvalue $<0.05$ was considered significant. The statistical analyses were performed using SAS software, version 9.2 (SAS Institute Inc., Cary, NC, USA). 


\section{Supplementary Table 1. Baseline clinical characteristics.}

\begin{tabular}{|c|c|c|c|}
\hline & $\begin{array}{l}\text { SYNTAX II } \\
(n=454)\end{array}$ & $\begin{array}{l}\text { SYNTAX-I PCI } \\
(n=315)\end{array}$ & $p$-value \\
\hline Age (years) & $66.7 \pm 9.7(454)$ & $66.7 \pm 9.1(315)$ & 0.99 \\
\hline Male & $93.2 \%(423 / 454)$ & $93.0 \%(293 / 315)$ & 0.93 \\
\hline Body mass index $\left(\mathrm{kg} / \mathrm{m}^{2}\right)$ & $28.9 \pm 4.7(449)$ & $28.2 \pm 4.4(315)$ & 0.032 \\
\hline Diabetes mellitus type 1 or 2 & $30.3 \%(135 / 446)$ & $29.2 \%(92 / 315)$ & 0.75 \\
\hline Insulin-treated & $8.5 \%(38 / 446)$ & $10.5 \%(33 / 315)$ & 0.36 \\
\hline Oral medication & $19.5 \%(87 / 446)$ & $16.8 \%(53 / 315)$ & 0.35 \\
\hline Diet only & $2.0 \%(9 / 446)$ & $1.9 \%(6 / 315)$ & 0.91 \\
\hline Current smoker & $14.7 \%(64 / 435)$ & $17.8 \%(56 / 315)$ & 0.26 \\
\hline Previous MI & $12.5 \%(56 / 44)$ & $28.7 \%(89 / 310)$ & $<0.001$ \\
\hline Previous stroke & $5.6 \%(25 / 449)$ & $1.9 \%(6 / 315)$ & 0.01 \\
\hline Hypertension & $77.0 \%(344 / 447)$ & $73.4 \%(229 / 312)$ & 0.26 \\
\hline Hyperlipidaemia & $77.3 \%(341 / 441)$ & $74.4 \%(232 / 312)$ & 0.35 \\
\hline Creatinine clearance $(\mathrm{ml} / \mathrm{min})$ & $82.0 \pm 26.9(454)$ & $87.3 \pm 28.5(315)$ & 0.008 \\
\hline $\operatorname{LVEF}(\%)$ & $58.1 \pm 8.3(454)$ & $61.8 \pm 11.3(315)$ & $<0.001$ \\
\hline Peripheral vascular disease & $7.7 \%(35 / 454)$ & $9.5 \%(30 / 315)$ & 0.37 \\
\hline COPD & $10.8 \%(49 / 454)$ & $12.7 \%(40 / 315)$ & 0.42 \\
\hline Clinical presentation & & & $<0.001$ \\
\hline Silent ischaemia & $5.5 \%(30 / 449)$ & $13.3 \%(42 / 315)$ & \\
\hline Stable angina & $68.8 \%(309 / 449)$ & $61.6 \%(194 / 315)$ & \\
\hline Unstable angina & $25.6 \%(115 / 449)$ & $25.1 \%(79 / 315)$ & \\
\hline Anatomic SYNTAX score & $20.3 \pm 6.4(454)$ & $22.8 \pm 8.7(315)$ & $<0.001$ \\
\hline SYNTAX score II PCI & $30.2 \pm 8.6(454)$ & $30.6 \pm 8.7(315)$ & 0.528 \\
\hline Predicted 4-year mortality PCI (\%) & $8.9 \pm 8.8(454)$ & $9.2 \pm 8.7(315)$ & 0.64 \\
\hline SYNTAX score II CABG & $29.1 \pm 10.4(454)$ & $29.1 \pm 9.6(315)$ & 1 \\
\hline Predicted 4-year mortality CABG (\%) & $9.0 \pm 9.3(454)$ & $8.5 \pm 8.1(315)$ & 0.44 \\
\hline
\end{tabular}

CABG: coronary artery bypass grafting; COPD: chronic obstructive pulmonary disease; LVEF: left ventricular ejection fraction; MI: myocardial infarction; PCI: percutaneous coronary intervention 
Supplementary Table 2. Lesion and procedural characteristics and medication.

\begin{tabular}{|c|c|c|c|}
\hline & SYNTAX II & SYNTAX-I PCI & $p$-value \\
\hline Lesions anatomical SYNTAX score per patient & $4.16 \pm 1.17(454)$ & $4.31 \pm 1.34(315)$ & 0.1 \\
\hline Lesions intended to be treated per patient & $3.49 \pm 0.97(447)$ & $4.6 \pm 1.55(311)$ & $<0.001$ \\
\hline Lesions treated per patient & $2.64 \pm 1.11(440)$ & $4.02 \pm 1.34(311)$ & $<0.001$ \\
\hline Stents per patient & $3.78 \pm 1.92(440)$ & $5.19 \pm 2.04(308)$ & $<0.001$ \\
\hline Stents per lesion & $1.43 \pm 0.76(1,165)$ & $1.28 \pm 0.65(1,251)$ & $<0.001$ \\
\hline \multicolumn{4}{|l|}{ Vessel assessed by physiology (iFR/FFR) } \\
\hline Left main & $0.9 \%(4 / 447)$ & N/A & \\
\hline $\mathrm{RCA}$ & $86.4 \%(386 / 447)$ & N/A & \\
\hline LAD & $98.9 \%(442 / 447)$ & N/A & \\
\hline $\mathrm{LCX}$ & $96 \%(429 / 447)$ & N/A & \\
\hline Assessment in three vessels & $82.8 \%(370 / 447)$ & & \\
\hline \multicolumn{4}{|l|}{ Vessel treated } \\
\hline Left main & $0.9 \%(4 / 441)$ & $2.3 \%(7 / 311)$ & 0.22 \\
\hline $\mathrm{RCA}$ & $60.5 \%(267 / 441)$ & $87.1 \%(271 / 311)$ & $<0.001$ \\
\hline LAD & $92.5 \%(408 / 441)$ & $99 \%(308 / 311)$ & $<0.001$ \\
\hline $\mathrm{LCX}$ & $67.1 \%(296 / 441)$ & $96.5 \%(300 / 311)$ & $<0.001$ \\
\hline Treatment in three vessels & $37.2 \%(164 / 441)$ & $83.3 \%(259 / 311)$ & $<0.001$ \\
\hline Mean stent length (per stent, mm) & $24.43 \pm 9.18(1,663)$ & $18.82 \pm 7.04(1,599)$ & $<0.001$ \\
\hline Total stent length (per patient, mm) & $92.32 \pm 52.78(440)$ & $97.71 \pm 43.66(308)$ & 0.13 \\
\hline Bifurcation treated $(\%)$ & $35 \%(159 / 454)$ & $60.6 \%(191 / 315)$ & $<0.001$ \\
\hline Total occlusion treated $(\%)$ & $27.8 \%(126 / 453)$ & $28.3 \%(89 / 315)$ & 0.88 \\
\hline Post-implantation IVUS MLA $\left(\mathrm{mm}^{2}\right)$ & $6.17 \pm 2.31(1,094)$ & N/A & \\
\hline \multicolumn{4}{|l|}{ Medication } \\
\hline \multicolumn{4}{|l|}{ Aspirin } \\
\hline At discharge & $99.8 \%(448 / 449)$ & $96.2 \%(302 / 314)$ & $<0.001$ \\
\hline At 1 month & $99.6 \%(443 / 445)$ & $93.9 \%(292 / 311)$ & $<0.001$ \\
\hline At 1 year & $95.6 \%(413 / 432)$ & $92.1 \%(278 / 302)$ & 0.046 \\
\hline At 2 years & $91.9 \%(391 / 429)$ & N/A & \\
\hline \multicolumn{4}{|l|}{$\mathrm{P} 2 \mathrm{Y}_{12}$ inhibitor } \\
\hline At discharge & $99.3 \%(446 / 449)$ & $98.4 \%(309 / 314)$ & 0.234 \\
\hline Clopidogrel & $66.8 \%(298 / 446)$ & N/A & \\
\hline Prasugrel & $4.5 \%(20 / 446)$ & N/A & \\
\hline Ticagrelor & $28.7 \%(128 / 446)$ & N/A & \\
\hline At 1 month & $99.6 \%(443 / 445)$ & $97.1 \%(302 / 311)$ & 0.004 \\
\hline Clopidogrel & $66.8 \%(298 / 446)$ & N/A & \\
\hline Prasugrel & $4.5 \%(20 / 446)$ & N/A & \\
\hline Ticagrelor & $28.7 \%(128 / 446)$ & N/A & \\
\hline DAPT at 1 year & $61.8 \%(267 / 432)$ & $72.2 \%(218 / 302)$ & 0.0034 \\
\hline DAPT at 2 years & $6.8 \%(29 / 429)$ & N/A & \\
\hline Statin at discharge & $97.3 \%(437 / 449)$ & $85.4 \%(268 / 314)$ & $<0.001$ \\
\hline Statin at 2 years & $92.3 \%(396 / 429)$ & N/A & \\
\hline
\end{tabular}


DAPT: dual antiplatelet therapy; FFR: fractional flow reserve; iFR: instantaneous wave-free ratio; IVUS: intravascular ultrasound; LAD: left anterior descending artery; LCX: left circumflex; MLA: minimal lumen area; PCI: percutaneous coronary intervention; RCA: right coronary artery 


\section{Supplementary Table 3. Achievement of SYNTAX II strategy.}

\begin{tabular}{lccc} 
& SYNTAX II & SYNTAX-I PCI & $p$-value \\
\hline SYNTAX score II calculated & $100 \%(454 / 454)$ & $100 \%(315 / 315)$ & 1.000 \\
iFR/FFR per patient & $96.4 \%(431 / 447)$ & NA & NA \\
iFR/FFR per lesion & $75.5 \%(1,177 / 1,559)$ & NA & NA \\
Post-stenting IVUS per patient & $84.1 \%(384 / 454)$ & $4.8 \%(15 / 311)$ & $<0.001$ \\
Post-stenting IVUS per lesion & $76.4 \%(872 / 1,142)$ & NA & NA \\
Success rate of CTO PCI per lesion & $87.0 \%(94 / 108)$ & $57.4 \%(54 / 94)$ & $<0.001$ \\
Current-generation DES used & $98.4 \%(440 / 447)$ & $0 \%(0 / 315)$ & $<0.001$ \\
& SYNERGY EES & TAXUS PES & \\
Statin at discharge & (strut thickness: $74 \mu \mathrm{m})$ & (strut thickness: $132 \mu \mathrm{m})$ & $<0.001$ \\
\hline
\end{tabular}

CTO: chronic total occlusion; DES: drug-eluting stent; FFR: fractional flow reserve; iFR: instantaneous wavefree ratio; IVUS: intravascular ultrasound; PCI: percutaneous coronary intervention 
Supplementary Table 4. Univariate and multivariate independent predictors of twoyear MACCE* in SYNTAX II.

\begin{tabular}{|c|c|c|c|c|c|c|}
\hline \multirow[b]{2}{*}{ Variables } & \multicolumn{3}{|c|}{ Univariable predictors at 2 years } & \multicolumn{3}{|c|}{ Multivariable predictors at 2 years } \\
\hline & HR & $95 \% \mathrm{CI}$ & $p$-value & HR & $95 \% \mathrm{CI}$ & $p$-value \\
\hline COPD & 2.835 & $1.556-5.165$ & 0.010 & 2.899 & $1.304-6.444$ & 0.009 \\
\hline Female sex & 2.508 & $1.190-5.285$ & 0.016 & 3.192 & $1.196-8.518$ & 0.200 \\
\hline Creatinine clearance (per $\mathrm{ml} / \mathrm{min}$ ) & 0.983 & $0.969-0.998$ & 0.022 & 0.987 & $0.972-1.002$ & 0.096 \\
\hline Peripheral vascular disease & 1.941 & $0.921-4.089$ & 0.081 & 3.377 & $1.323-8.624$ & 0.011 \\
\hline Previous MI & 1.533 & $0.776-3.031$ & 0.219 & 1.637 & $0.677-3.959$ & 0.274 \\
\hline Anatomic SYNTAX score & 1.024 & $0.985-1.064$ & 0.226 & 1.051 & $1.002-1.101$ & 0.040 \\
\hline Hypertension & 1.330 & $0.690-2.564$ & 0.395 & & & \\
\hline Diabetes mellitus & 1.222 & $0.711-2.099$ & 0.469 & & & \\
\hline Current smoking & 1.152 & $0.564-2.354$ & 0.697 & & & \\
\hline Age (years) & 1.005 & $0.979-1.032$ & 0.713 & & & \\
\hline Hyperlipidaemia & 0.904 & $0.496-1.650$ & 0.743 & & & \\
\hline LVEF (per \%) & 0.999 & $0.969-1.029$ & 0.933 & & & \\
\hline
\end{tabular}

* MACCE was defined as all-cause death, any stroke, MI, or revascularisation.

COPD: chronic obstructive pulmonary disease; LVEF: left ventricular ejection fraction; MACCE: major adverse cardiac and cerebrovascular events; MI: myocardial infarction; PCI: percutaneous coronary intervention 
Supplementary Table 5. Revascularisation at two years ${ }^{1}$ in the SYNTAX II study.

Outcome

SYNTAX II

Any revascularisation $(\mathrm{n}=\mathbf{4 5 4})^{2}$

Target vessel $10.2 \%(45)$

Clinically driven $8.6 \%(38)$

Non-clinically driven $6.8 \%(30)$ $2.0 \%(9)$

Target lesion $8.1 \%(36)$

Clinically driven $6.4 \%(28)$

Non-clinically driven $1.8 \%(8)$

Target vessel-non target lesion $1.6 \%(7)$

Clinically driven $1.4 \%(6)$

Non-clinically driven

Non-target vessel

$2.0 \%(9)$

CABG

$1.1 \%(5)$

Target vessel

$1.1 \%(5)$

Clinically driven

$1.1 \%(5)$

Non-clinically driven

$0.2 \%(1)$

Target lesion

Clinically driven

$1.1 \%(5)$

Non-clinically driven

$0.0 \%(0)$

Target vessel-non target lesion

$0.7 \%(3)$

Clinically driven

$0.5 \%(2)$

Non-clinically driven

$0.2 \%(1)$

Non-target vessel

$0.5 \%(2)$

\section{Re-PCI}

$9.3 \%(41)$

Target vessel

$7.7 \%(34)$

Clinically driven

Non-clinically driven

Target lesion

Clinically driven

Non-clinically driven

Target vessel-non target lesion

Clinically driven

Non-clinically driven

Non-target vessel

${ }^{1}$ two years: 730 days; ${ }^{2}$ Kaplan-Meier estimates.

CABG: coronary artery bypass grafting; PCI: percutaneous coronary intervention 


\section{Major Adverse Cardiac or Cerebrovascular Events}

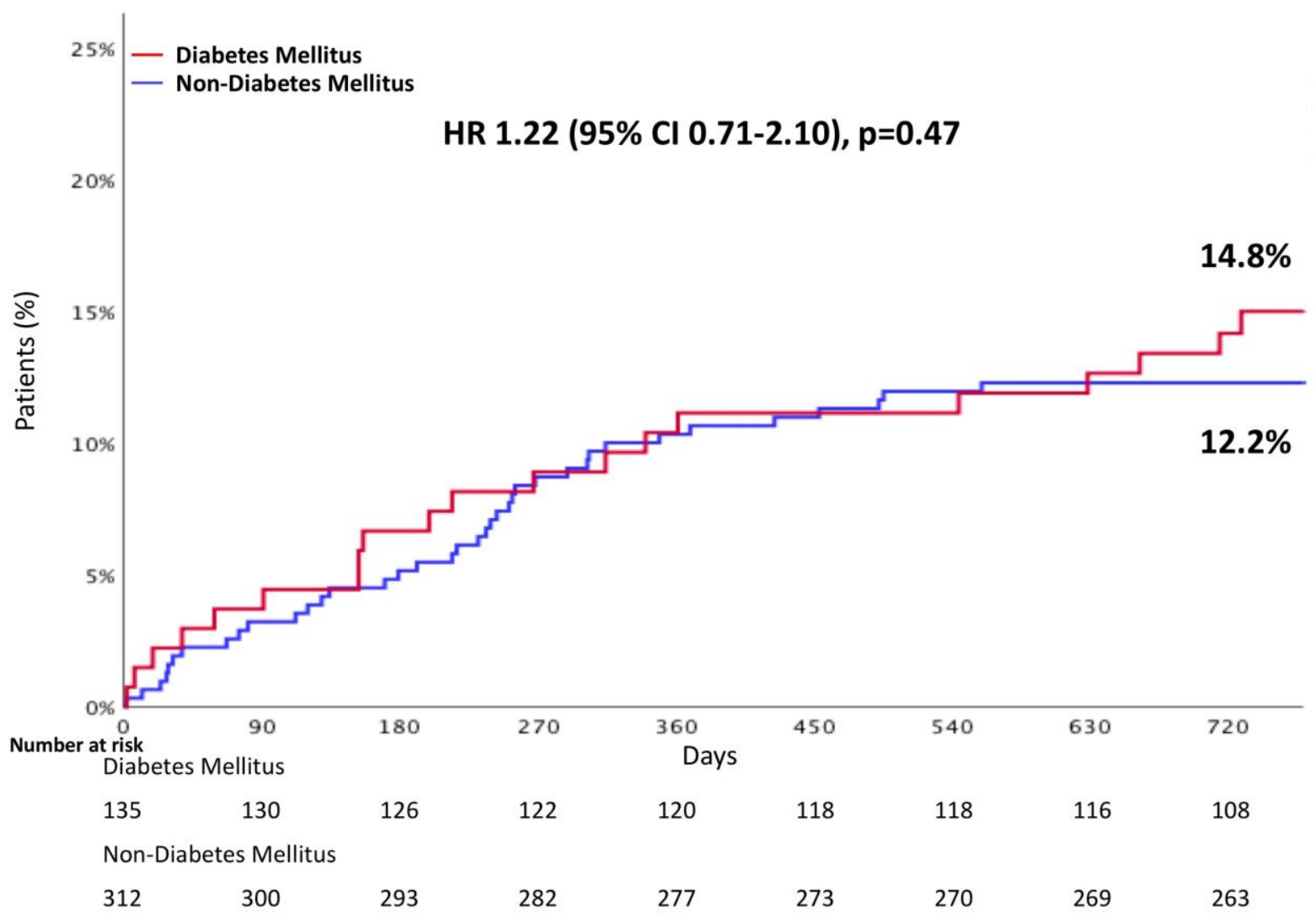

Supplementary Figure 1. Kaplan-Meier cumulative incidence for major adverse cardiac or cerebrovascular events in SYNTAX II patients stratified by diabetes mellitus (red) and nondiabetes mellitus (blue). 
Major Adverse Cardiac or Cerebrovascular Events

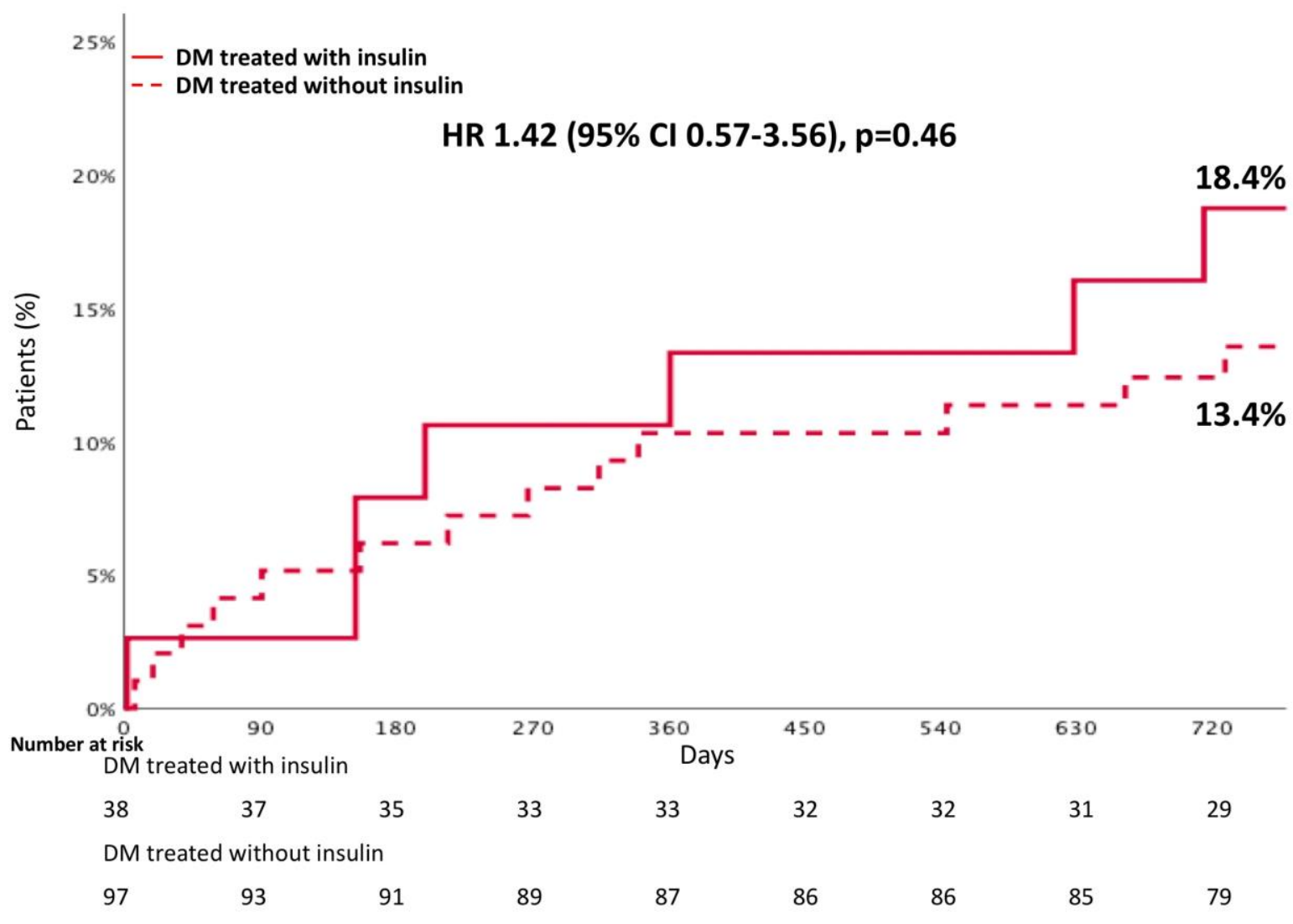

Supplementary Figure 2. Kaplan-Meier cumulative incidence for major adverse cardiac or cerebrovascular events in SYNTAX II patients with diabetes mellites stratified by insulin treated (red) and non-insulin treated (red broken). 